\title{
A new class of transparent organic particles in seawater visualized by a novel fluorescence approach
}

\author{
Ty J. Samo*, Francesca Malfatti, Farooq Azam \\ Marine Biology Research Division, Scripps Institution of Oceanography, University of California San Diego, La Jolla, \\ California 92093, USA
}

\begin{abstract}
A method for visualizing transparent material in seawater, described here, has led to the discovery of novel particles. The protocol is based on Alcian Blue and SYBR Gold staining of seawater samples on polycarbonate filters. While the particles detected by our method may have some overlap with previously described transparent exopolymer particles and Coomassie stained particles, these particles largely comprise a previously undetected class. We propose that the particles are detected because they cause spatially explicit inhibition of Alcian Blue quenching of SYBR Gold fluorescence of the filter. Samples collected from various locations (Ellen Browning Scripps Memorial Pier, California, the Palmer Peninsula, Antarctica, and Point Conception, California) revealed particles with abundances on the order of 10 and $10^{5} \mathrm{l}^{-1}$ and ranging in size from 10 to $10^{5} \mu \mathrm{m}^{2}$. The particles varied in the types of organisms attached, the internal structure and probable biological sources. Field observations and laboratory experimental manipulations suggest varied sources and mechanisms of formation. These particles are potential hot spots of organic matter, microbial diversity and interactions, and, depending on their size and sinking rates, serve as conduits for carbon export to the ocean's interior.
\end{abstract}

KEY WORDS: Transparent organic particles · Seawater - Alcian Blue $\cdot$ SYBR Gold fluorescencebased visualization

\section{INTRODUCTION}

A challenging goal of microbial oceanography is to understand the role of organic matter and its interactions with microorganisms in the functioning of marine ecosystems. Marine organic matter exhibits great variations in its sources and characteristics, such as biodegradability, charge, chemical composition, microbial colonization, density, molecular weight, optical characteristics, size, shape, stickiness and viscosity. Further, the organic matter can undergo biological, chemical and physical transformations while also participating in oceanic biogeochemical processes (Isao et al. 1990, Passow \& Alldredge 1994, Aluwihare et al. 1997, Chin et al. 1998, Azam \& Worden 2004, Orellana et al. 2007). These processes include the cycling of carbon, nutrients and trace metals, carbon flux to the deep ocean, bloom dynamics, and the formation and dissolution of organic matter mediated by microbial activities.
Marine organic matter is often divided operationally between dissolved organic matter (DOM) and particulate organic matter (POM) on the basis of filterability through 0.45 to $1.7 \mu \mathrm{m}$ pore size filters. The POM components have been characterized by microscopic observations and the binding specificity of several stains (Mostajir et al. 1995, Long \& Azam 1996, Johnsen et al. 2000). For example, the production of transparent exopolymer particles (TEP) has been attributed to phytoplankton, notably diatoms. TEP may be chemically complex, have a wide range of sizes and morphologies and may be created and modified by a myriad of biological, chemical and physical interactions (Alldredge et al. 1993). TEP may also be colonized by bacteria, presumably serving as a niche for them, but it may also be modified by bacterial activities (Verdugo et al. 2004, Azam \& Malfatti 2007). Bacteria-organic matter interactions at nanometer to millimeter scales may play a role in microbial loop dynam- 
ics, affect carbon fluxes and the biological pump and influence ecosystem functioning (Azam \& Long 2001, Long \& Azam 2001, Simon et al. 2002, DeLong \& Karl 2005). Microbiological studies have yielded insights on the relationship between organic matter and the roles microbes play in structuring the organic matter in their microenvironments through release, uptake and degradation of organic matter (Smith et al. 1995, Aluwihare \& Repeta 1999, Radic et al. 2006). It is, therefore, important to know the in situ microscale characteristics of organic matter and the mechanisms of its formation and degradation, as context for understanding how the biochemical interactions of bacteria with organic matter influence their ecology and the functioning of marine ecosystems.

Imaging of bacteria and the organic matter in their microenvironment is becoming tractable with the advent of sensitive labeling and optical techniques. Thus, the proverbial drop of seawater may soon be observed from the microbial point of view. Just as the use of fluorescent DNA stains enabled visualization of marine bacteria, so too have certain dyes been applied to seawater to attain glimpses of their microscale environments. TEP is made visible by staining with Alcian Blue (Alldredge et al. 1993) and proteinaceous particles in seawater are visualized with Coomassie Blue (Coomassie stained particles [CSP]; Long \& Azam 1996). The current techniques, in conjunction with 4 '-6diamidino-2-phenylindole (DAPI) to stain microbes, suggest that transparent polymeric and suprapolymeric loci of organic matter represent environments in which viruses, prokaryotes and eukaryotes are brought into close contact (Proctor \& Fuhrman 1991). These observations have led to the concept that organic matter in seawater occurs as a heterogeneous continuum ranging in size from nanometers to millimeters (Azam et al. 1993, Verdugo et al. 2004), and the proposal that such environmental heterogeneity is important in microbial ecology, diversity and biogeochemistry (Long \& Azam 2001, Kiørboe et al. 2003, Grossart et al. 2006, Azam \& Malfatti 2007).

The current staining methods, however, do not stain lipid, cationic or uncharged polysaccharide, DNA or humic acids, materials that may also be important components of the transparent particle field. Further, some particles may be too small to be discerned by optical microscopy. Using transmission electron microscopy Wells \& Goldberg (1991) discovered highly abundant $\left(10^{8}\right.$ to $\left.10^{9} \mathrm{ml}^{-1}\right)$ colloids from $20 \mathrm{~nm}$ to hundreds of nanometers in size. We made a number of unsuccessful attempts to constrain the hypothesis that the currently visualized organic matter is but a minor fraction of the organic matter continuum. Based on the results of positive controls, we hypothesized that many components of transparent organic matter are too dilute to visualize by the current protocols. We found that a protocol combining prolonged staining with Alcian Blue followed by staining with SYBR Gold revealed a new population of particles not seen by previous methods. On the basis of their general appearance and proposed mechanism of visualization, we have named them filter fluorescing particles (FFP). These particles provide new insights into our view of the microbial world and microbial biogeochemical functions.

\section{MATERIALS AND METHODS}

Sampling and staining. Seawater was sampled with a polycarbonate flask from Ellen Browning Scripps Memorial Pier (Scripps Pier), La Jolla, California $\left(32^{\circ} 52.02^{\prime} \mathrm{N}, 117^{\circ} 15.43^{\prime} \mathrm{W}\right), \mathrm{USA}$, at $\sim 1 \mathrm{~m}$ depth. Water was also collected during cruises via deployment of a CTD rosette at depths up to $750 \mathrm{~m}$. Samples were processed within 10 to $120 \mathrm{~min}$, or stored at in situ temperature until used, and fixed with formaldehyde $(2 \%$ final concentration) unless otherwise noted. Samples, 2 to $120 \mathrm{ml}$ in volume, were filtered through white 0.22 or $1 \mu \mathrm{m}$ pore size polycarbonate filters (at $\leq 20 \mathrm{kPa}$ ) until no liquid remained, then stained with $0.5 \mathrm{ml}$ of $1 \times$ Alcian Blue for $30 \mathrm{~s}$. Suction was re-applied to filter the stain. Alcian Blue was prepared as an aqueous solution containing $0.04 \%$ Alcian Blue (w/v) plus $0.12 \%$ acetic acid (v/v) in Milli-Q water and diluted $2 \times$ and filtered $(0.22 \mu \mathrm{m})$ before use. The filter was then placed on $80 \mu$ l of $1 \times$ or $5 \times$ SYBR Gold (Invitrogen) that was first prepared and filtered $(0.22 \mu \mathrm{m})$ with Millli-Q water or seawater. Staining times ranged from 3 to $20 \mathrm{~min}$. Filters were then dried on paper towels and mounted on glass slides with Resolve ${ }^{\circledR}$ immersion oil.

Visualization. Samples were examined with an Olympus IX-71 inverted microscope at 200×,600×, and $1000 \times$ magnifications using transmitted light or epifluorescence illumination (excitation: $488 \mathrm{~nm}$; emission: long pass filter). Depending on sample location, seconds to minutes were needed to find a fluorescing particle. Cyto-Clear slides (GE Osmonics) were placed on top of the sample slides to allow visualization in transmitted light. Images were recorded with an Olympus Microfire digital camera using PictureFrame software. Additionally, some filters were observed at 1000× magnification with a Nikon laser scanning confocal microscope. Images were obtained using using EZCI software coupled to 488 and $543 \mathrm{~nm}$ excitation lasers with broad green and red emission filters.

Counting and sizing. Abundance and size of the particles were determined at $600 \times$ magnification. Forty random fields were visualized on each filter and the particles in a $10 \times 10$ ocular grid or the entire field of view were counted and sized (with the ocular grid). 
Samples with very low abundance of particles were counted in transects across one-half or a whole filter. Areas were calculated by measuring length and width to the nearest one-quarter ocular grid square.

Blanks. Negative controls were prepared to determine the potential for SYBR Gold-mediated aggregation of ambient dissolved macromolecules. These controls included the standard Alcian Blue and SYBR Gold staining of the following $10 \mathrm{ml}$ samples: (1) freshly prepared and sterilized ZoBell media diluted to 1/1000 and 1/10000 concentrations; (2) supernatant taken from $13 \mathrm{ml}$ of whole seawater centrifuged at $16000 \times \mathrm{g}$ for $10 \mathrm{~min}$; and (3) filtrate from whole seawater passed through a $0.22 \mu \mathrm{m}$ filter. To mirror the treatment of natural samples, formaldehyde was added to each control to a final concentration of $2 \%$. Finally, $10 \mathrm{ml}$ of unmanipulated, whole seawater used for the filtrate and centrifugation blanks was fixed and stained.

Additional manipulations and staining protocols were developed to fully illustrate that these structures did not result from an interaction between SYBR Gold and molecules in natural seawater samples. We collected four $10 \mathrm{ml}$ seawater samples from the Scripps Pier. These were $0.2 \mu \mathrm{m}$ filtered and fixed with $0.02 \mu \mathrm{m}$ filtered formaldehyde ( $2 \%$ final concentration). Approximately $450 \mathrm{ml}$ of extra $0.2 \mu \mathrm{m}$ filtered seawater was then cycled through a $100 \mathrm{kDa}$ tangential flow filtration column until $300 \mathrm{ml}$ was collected. This volume provided four $10 \mathrm{ml}$ samples, which were subsequently fixed. From each filtration, 2 samples were filtered and stained with the standard protocol. The remaining 4 samples were incubated at room temperature with $1 \times$ SYBR Gold for 15 min, filtered, stained with Alcian Blue and counted. The role of temperature in the formation of FFP was also investigated by performing the standard staining proto$\mathrm{col}$ at room temperature or at $4^{\circ} \mathrm{C}$. Counts were performed at room temperature and $4^{\circ} \mathrm{C}$ through the use of a cooling stage connected to the microscope.

Fixed versus unfixed samples. We prepared triplicate seawater samples with or without formaldehyde fixation, but otherwise used the standard protocol described for the samples.

Cell lysis artifacts. We considered that filtration might have lysed delicate phytoplankton and that separating the phytoplankton from the particles with gentle centrifugation might minimize cell lysis. Seawater samples were centrifuged slowly $(100 \times g)$, and abundance and size compared between supernatant and pellet. Conical $15 \mathrm{ml}$ tubes, each containing $10 \mathrm{ml}$ seawater, were centrifuged for $5 \mathrm{~min}$. The top $7 \mathrm{ml}$ and bottom $3 \mathrm{ml}$ were filtered and stained.

Phytoplankton artifacts. Non-axenic, stationary phase phytoplankton cultures of Thalassiosira weissflogii, Cylindrotheca, fusiformis, Chaetoceros gracilis and Lingulodinium polyedrum were diluted 1:100 in
$0.22 \mu \mathrm{m}$ filtered seawater, which had been autoclaved. Aliquots of $1 \mathrm{ml}$ were filtered on $1 \mu \mathrm{m}$ polycarbonate membranes and the membrane was stained with Alcian Blue and SYBR Gold, as described previously.

Preparations of stains, filters and samples. To understand why and how our protocol enabled visualization of FFP, several variations of the protocol were tested:

(1) Filter seawater; stain with SYBR Gold (0.5 ml, 1×, $30 \mathrm{~s})$; stain with Alcian Blue (15 min); while membrane stays on the filter base.

(2) Pre-stain the filter $2 \times$ with Alcian Blue on the filter base ( $1 \mathrm{ml}, 1 \mathrm{~min})$, filter, then place the filter on a drop of SYBR Gold.

(3) Pre-stain the filter $5 \times$ with $0.5 \mathrm{ml}$ Alcian Blue, filter, then stain with SYBR Gold.

(4) Add SYBR Gold to seawater (1× final), incubate (10 min) then filter.

(5) Stain samples where indicated by the standard SYBR Green protocol of Noble \& Fuhrman (1998).

(6) Test different filter types and pore sizes to see whether they provide better visualization: $0.45 \mu \mathrm{m}$ white cellulose filter (Micron Separations), $0.02 \mu \mathrm{m}$ white $\mathrm{AlO}_{2}$ filters (Whatman), and $0.2 \mu \mathrm{m}$ white or black polycarbonate filters (Whatman).

(7) Test several other histological stains to see whether they help visualize additional features: Ruthenium Red (0.001 and 0.02\%), Crystal Violet (0.1\%), and Coomassie Blue $(0.04 \%)$. Filter-retained samples were stained with $0.5 \mathrm{ml}$ for $30 \mathrm{~s}$, followed by standard SYBR Gold protocol.

(8) Test whether the stained FFP could be resuspended. Filter-retained samples (vacuum or gravity filtered) were stained with Alcian Blue, placed on a drop of SYBR Gold for $10 \mathrm{~min}$, then placed in a Petri dish and vigorously rinsed (using a pipette) 10 times with $2 \mathrm{ml}$ autoclaved $0.22 \mu \mathrm{m}$ filtered seawater. The suspension was filtered and stained once again. Controls were prepared by omitting the seawater rinse.

(9) Subject seawater samples to several treatments prior to filtration and compare with controls: (1) $50 \mathrm{mM}$ (final) EDTA was added to see whether disrupting divalent cation cross-linking would disperse the FFP organic matter; (2) Triton X-100 (1\% final) was added to seawater, which was then sonicated (full power, 1 min; Sonic Dismembrator, Fisher Scientific), stained and visualized; (3) after filtering samples, the filters were dried $\left(60^{\circ} \mathrm{C}, 30 \mathrm{~min}\right.$ in a hybridization oven).

Characterization. We attempted to produce particles that might mimic the FFP by adding varying concentrations of several types of macromolecules (DNA, lipid, protein) and hydrolytic enzymes to the filters. Samples were then filtered and stained as in our protocol.

(1) Herring sperm DNA (D181B, Promega) was diluted in the following solutions: de-ionized water 
(Milli-Q) to $1 \mathrm{mg} \mathrm{ml}^{-1}, 100 \mu \mathrm{g} \mathrm{ml}^{-1}, 10 \mu \mathrm{g} \mathrm{ml}^{-1}$ and $1 \mu \mathrm{g}$ $\mathrm{ml}^{-1} ; 10 \%$ bovine serum albumin (BSA) in Milli-Q water; $1 \%$ agarose in autoclaved $0.22 \mu \mathrm{m}$ filtered seawater. The solutions were spotted once on the filters, stained and visualized.

(2) BSA was added to an aliquot of agarose at $10 \%$ final concentration and DNA was prepared similarly in agarose at $10 \mu \mathrm{g} \mathrm{ml}^{-1}$. The agarose, BSA, agarose + BSA and agarose + DNA was then spotted on the filter and prepared for visualization.

(3) A spotting experiment with 2 different solutions of phosphatidylcholine: $5 \mathrm{mg} \mathrm{m}^{-1}$ in $100 \%$ ethanol then diluted to $2.5 \mathrm{mg} \mathrm{ml}^{-1}$ or $50 \mu \mathrm{g} \mathrm{ml}^{-1}$ in autoclaved filtered seawater. Then $100 \mu \mathrm{l}$ of $5 \mathrm{mg} \mathrm{ml}^{-1}$ phosphatidylcholine in ethanol was subjected to evaporation to remove the alcohol. A $1 \mathrm{mg} \mathrm{ml}^{-1}$ phosphatidylcholine solution was prepared by adding $500 \mu$ l of autoclaved and filtered seawater to the remaining lipid residue. Solutions were spotted on filters, stained and visualized. Ethanol spots served as control.

(4) Treatments with hydrolytic enzymes were done to infer macromolecular composition of FFP and determine whether the enzymes would cause FFP to disintegrate into smaller particles: DNase $\left(80 \mathrm{U} \mathrm{ml}^{-1}, 30 \mathrm{~min}\right)$, lipase (10 $\left.\mathrm{U} \mathrm{ml}^{-1}, 20 \mathrm{~min}\right)$, pronase $\left(5 \mathrm{U} \mathrm{ml}^{-1}, 20 \mathrm{~min}\right)$ and $\beta$-glucosidase (10 $\left.\mathrm{U} \mathrm{ml}^{-1}, 20 \mathrm{~min}\right)$. Samples were filtered and stained, and the FFP were counted, sized and compared with untreated samples.

Staining with fluorescently labeled lectins. Tetramethylrhodamine labeled peanut agglutinin and concanavalin A were used to target the D-galactose and both D-glucose and D-mannose residues, respectively, in the FFP. Seawater was filtered and stained with Alcian Blue as per the protocol, but then were stained for $3 \mathrm{~min}$ with $1 \times$ SYBR Gold. The filter was placed back on the filter base and suctioned to dryness, then transferred to a Petri dish and $100 \mu$ l of each lectin (5 $\mu \mathrm{g} \mathrm{ml}^{-1}$ final concentration) was added on top. Samples were incubated in the dark for $20 \mathrm{~min}$.

Nitrogen and phosphorous amendment. We considered that the nutrient status of seawater could highlight links between the sources of FFP and microbial physiology and metabolism. Since phytoplankton release large amounts of marine organic carbon and their health is affected by inorganic nutrient availability, we hypothesized that a measurable FFP response would be observed following a pulse of limiting nutrients. We added $\mathrm{KH}_{2} \mathrm{PO}$ or $\mathrm{NH}_{4} \mathrm{Cl}$ and $\mathrm{KH}_{2} \mathrm{PO}$ at $1 \mu \mathrm{M}$ final concentrations to 11 seawater in duplicate polycarbonate bottles and incubated at $14^{\circ} \mathrm{C}$ on a shaker at $70 \mathrm{rpm}$. Unamended seawater was stained and analyzed for FFP abundance and dimensions. After $10 \mathrm{~d}$, a subsample was taken from each bottle, stained and analyzed for FFP abundance and dimensions.

\section{RESULTS AND DISCUSSION}

\section{Initial observations}

Appearance and distribution

Seawater samples filtered on $1 \mu \mathrm{m}$ polycarbonate membranes and stained with Alcian Blue followed by SYBR Gold ('standard protocol') showed bright regions of yellow-green fluorescence. At 600× and 1000× magnification they appear as fluorescent groupings of filter pores occasionally connected by mucus-like material. (Fig. 1A,B). We first observed them (July 2005) during a Lingulodinium polyedrum bloom while testing whether bacterial colonization of TEP previously seen by double staining with Alcian Blue plus DAPI (Alldredge et al. 1993) might be better visualized with Alcian Blue plus SYBR Gold. We have subsequently detected FFP in samples from Scripps Pier as well as from nearshore and offshore stations in the Drake Passage and Bransfield Strait, Antarctica, in August 2006 and waters off of Point Conception, California, during April 2007 (Table 1). An excellent fluorescence signal from the microbes was obtained in some but not all areas of the filter, and in other regions brightly fluorescing shapes were present and occasionally showed an association with bacteria and protozoa.

While FFP were observed in geographically separate and distinct locations, both similarities and differences in FFP appearance were observed. Samples were visualized with confocal microscopy to better observe these subtle characteristics (Fig. 2). The side view of the particles suggested that the filter pore fluorescence does not extend upward and out from the surface, supporting an indirect staining mechanism that does not rely on binding of the stain to the particle. Inspection of the side views from several samples suggests that the extension of the fluorescing pores is variable, anywhere from 4 to $13 \mu \mathrm{m}$ deep. This led to the observation that all of the filter pores actually display a small amount of SYBR Gold fluorescence and can be clearly seen by increasing the gain function of the confocal microscope. Most of these 'quenched' pores decrease in intensity and become undetectable below $6 \mu \mathrm{m}$ into the filter pores. In some cases it was apparent that the SYBR Gold did attach to some portion of the particle and resulted in a protrusion of a bright yellow-green structure. Samples from Scripps Pier could be characterized by brightly fluorescing material and chlorophyll exhibiting a FFP signal while also sometimes associating with various phytoplankton, protozoa, and bacteria (Fig. 2A). These types of FFP signals could also be described as fairly 'robust', i.e. the fluorescence was intense and confined to a discrete area. Initial observations would suggest that FFP from the Califor- 

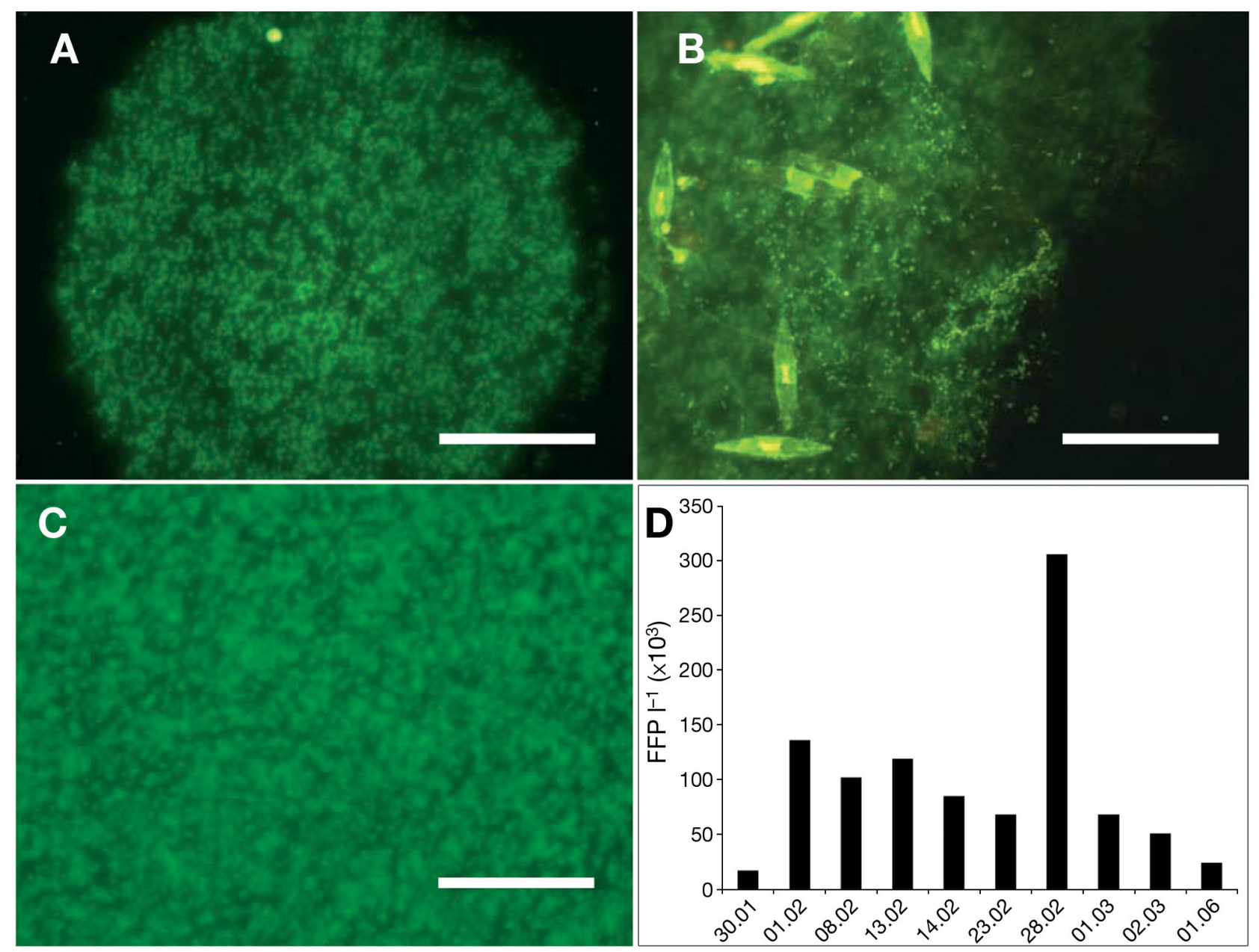

Fig. 1. (A-C) Filter fluorescing particles (FFP) in Scripps Pier seawater filtered onto $1 \mu \mathrm{m}$ pore size polycarbonate filters and visualized by the staining protocol described in the text. Each fluorescing spot is a single $1 \mu \mathrm{m}$ diameter pore that emits a bright green SYBR Gold fluorescence signal. In addition to the roughly circular shape in (A) a wide range of shapes were observed, e.g. (B), which is a FFP associated with high concentrations of bacteria and diatoms. (C) Image of a filter prepared without Alcian Blue. (D) Abundances of FFP determined in waters off Scripps Pier periodically during January to June 2006 (dates given as DD.MM). Magnification $=600 \times$, scale bars $=50 \mu \mathrm{m}$

nia Current were similar to those from Scripps Pier. Microbial attachment and connections to other fluorescent structures were again seen, but periodically showed dissimilar morphologies and associations. For example, a coat of hazy fluorescence was seen around seemingly random FFP regions and when the focal plane was adjusted farther into the sample, the fluorescing filter pores could then be easily discerned (Fig. 2D). Antarctic FFP were rarely colonized by microbes and were not usually seen near or containing fluorescing material. The pore fluorescence varied from a 'typical' signal observed in all samples to bright pores localizing with a relatively bright filter surface (e.g. Fig. 2G) to dim pores that seemed to become brighter farther within. It remains unclear whether these differences were a result of SYBR Gold

Table 1. Sampling site locations and environmental types, and collection dates

\begin{tabular}{|lrcc|}
\hline Location & Coordinates & Environment & Collection date \\
\hline Scripps Pier & $32^{\circ} 52.02^{\prime} \mathrm{N}$, & Coastal & 28 Feb 2006 \\
& $117^{\circ} 15.43^{\prime} \mathrm{W}$ & & \\
Palmer Peninsula, & $62^{\circ} 11.93^{\prime} \mathrm{S}$, & Coastal & 7 Jul 2006 \\
Antarctica & $58^{\circ} 8.28^{\prime} \mathrm{W}$ & & \\
& $60^{\circ} 37.00^{\prime} \mathrm{S}$, & Open ocean & 21 Jul 2006 \\
& $54^{\circ} 37.48^{\prime} \mathrm{W}$ & & \\
California Current & $34^{\circ} 16.30^{\prime} \mathrm{N}$, & Near shore & 8 Apr 2007 \\
near Point Conception & $121^{\circ} 9.95^{\prime} \mathrm{W}$ & & \\
& $33^{\circ} 20.48^{\prime} \mathrm{N}$, & Offshore & 12 Apr 2007 \\
& $123^{\circ} 32.07^{\prime} \mathrm{W}$ & & \\
\hline
\end{tabular}



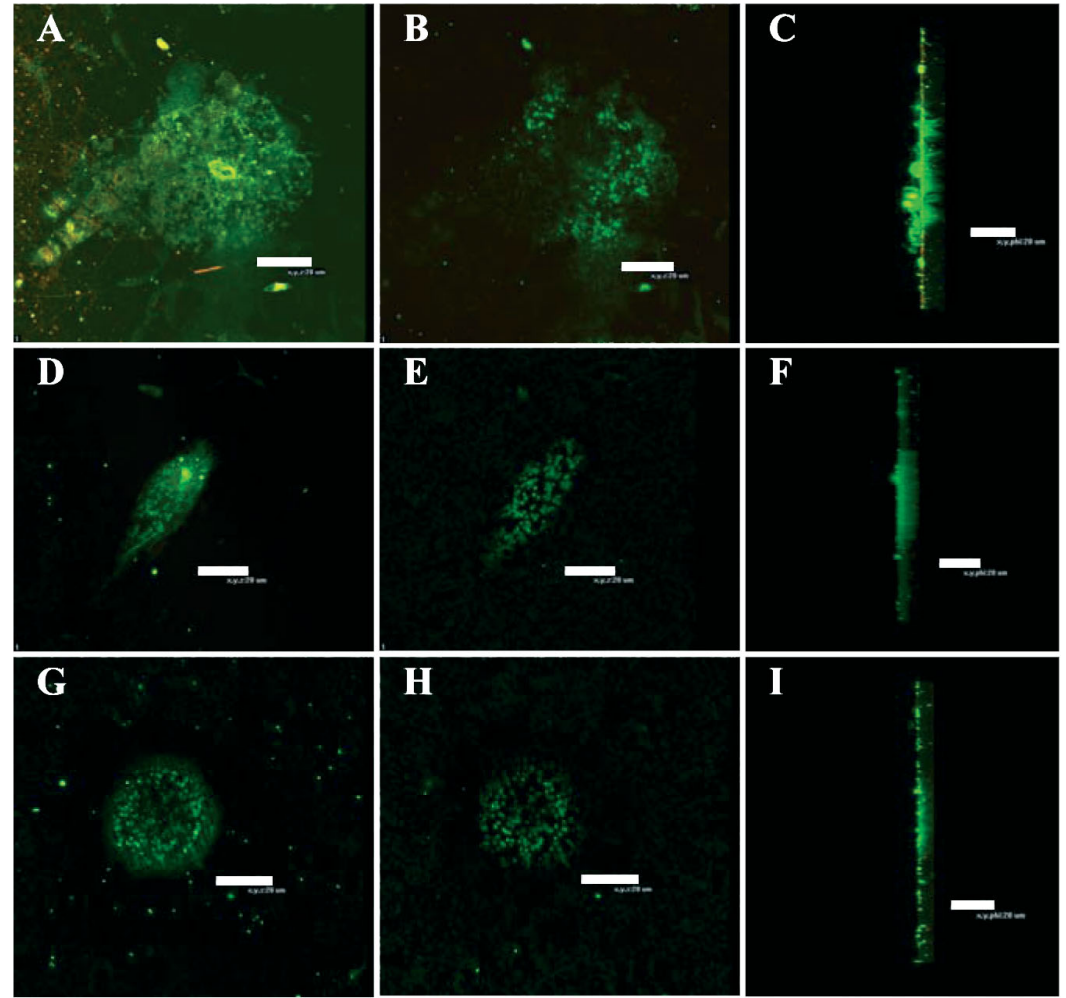

Fig. 2. Confocal images of FFP in seawater from (A-C) Scripps Pier, (D-F) the California Current and $(G-I)$ Antarctica. $(A, D, G)$ Images are scans of the surface of the particles and represent what would be seen if observing with regular epifluorescence microscopy. (B,E,H) Image slices taken approximately $3 \mu \mathrm{m}$ below the surface. $(C, F, I)$ Side view images of the particles obtained from a 3D rendering of the confocal scan. Scale bars $=20 \mu \mathrm{m}$

binding to an organic surface film or whether the properties of the particle caused some alteration in the emitted light. A combination of these explanations may also be plausible since the green light emitted from SYBR Gold stainable substances shows $2 \mathrm{~nm}$ differences in emission spectra (data not shown). Thus, for the FFP to be visualized, the binding target of the stain may be as important as the environment on the filter in which it occurs. Additional observations and experiments are required for further elucidation of the mechanism of visualization.

\section{Abundance and dimensions}

Abundances from the sampled locations ranged from 10 to $5 \times 10^{5} \mathrm{l}^{-1}$. Abundance in the water from Scripps Pier exhibited nearly $10 \times$ variability on timescales of days, weeks and months (Fig. 1D). FFP on the same filter and among filters were dispersed randomly and differed in brightness and hue of the fluorescence. These differences could be due to variation in SYBR Gold staining of filters or the composition of FFP.
The particles occasionally harbored attached microbes, including bacteria and cyanobacteria, diatoms, dinoflagellates and other protists. However, an approximately equal number showed no association with microbes. Associations with other components of the particulate organic matter, e.g. SYBR Gold stained material as well as TEP, was also seen.

The samples collected during cruises in the California Current and Antarctica Peninsula generally showed decreasing trends in abundance with depth. In some samples, however, abundances reached a maximum that tends to coincide with both chlorophyll increases and decreases in light transmission (Fig. 3). In these environments we hypothesize that the densities of seawater and FFP may result in concentrated patches due to settling on isopycnal surfaces. These may be sites of enhanced remineralization by bacteria as well as influential locales of carbon export brought about by abrupt changes in stratification. Cursory assessments provide support for this notion, but additional and more precise samplings are needed.

A variety of shapes and sizes were observed at 100× $200 \times, 600 \times$ and $1000 \times$ magnifications. Circular, elongated and irregular shapes were present in all samples, with irregularshaped material dominating most samples. Areas ranged from 1 to $10^{5} \mu^{2}$. However, it is probable that filtration or mounting on slides altered the shapes. A method is needed to image them in 3D as they occur in seawater.

\section{Control experiments}

SYBR Gold is part of a family of positively charged, asymmetrical cyanine dyes that bind to double and single stranded DNA and RNA targets through base pair intercalation as well as attachment to the minor groove and phosphate backbone via ionic binding (Zipper et al. 2004). We considered that the hydrophobicity of SYBR Gold for intercalation reaction potentially caused aggregation of molecules at the filter surface. However, the results of negative controls did not support this possibility. The $0.22 \mu \mathrm{m}$ filtered seawater blanks did not exhibit any FFP, suggesting that the particles were not due to SYBR Gold medi- 
A

\begin{tabular}{|c|c|c|c|c|}
\hline \multicolumn{5}{|c|}{$\mathrm{FFP} \mathrm{I}^{-1}\left(x 10^{3}\right)$} \\
\hline 0 & 0.2 & 0.4 & 0.6 & 0.8 \\
\hline \multicolumn{5}{|c|}{$\mathrm{Chl} a\left(\mathrm{mg} \mathrm{m}^{-3}\right)$} \\
\hline 0 & 0.02 & 0.04 & 0.06 & 0.08 \\
\hline
\end{tabular}

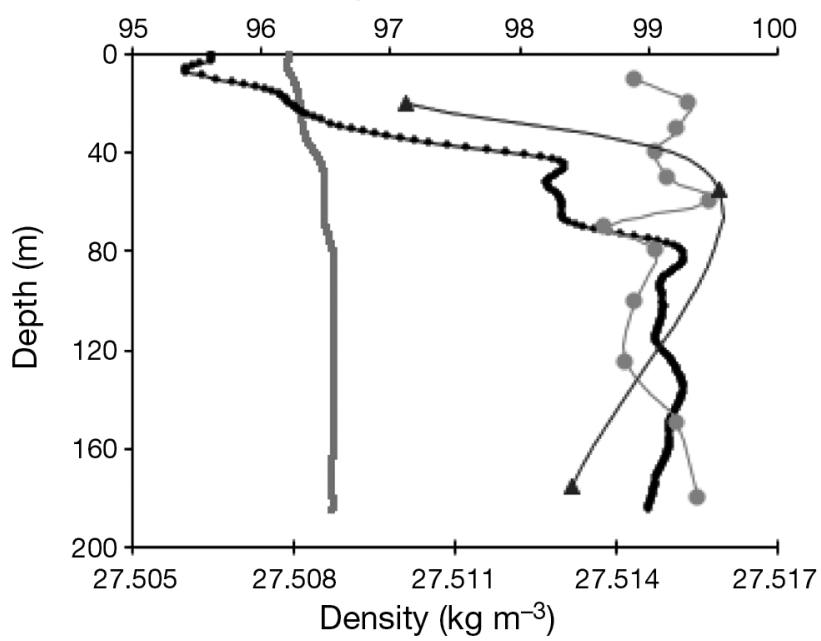

C

\begin{tabular}{|c|c|c|c|c|}
\hline \multicolumn{5}{|c|}{ FFP I-1 $\left(x 10^{3}\right)$} \\
\hline 0.0 & 2.0 & 4.0 & 6.0 & 8.0 \\
\hline \multicolumn{5}{|c|}{$\mathrm{Chl} a\left(\mathrm{mg} \mathrm{m}^{-3}\right)$} \\
\hline 0.0 & 0.3 & 0.5 & 0.8 & 1.0 \\
\hline
\end{tabular}

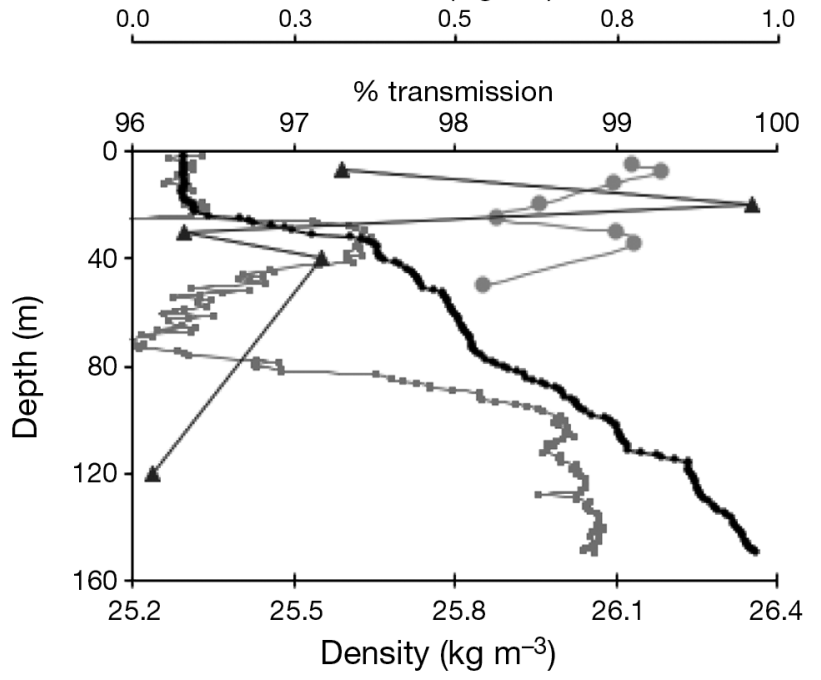

B

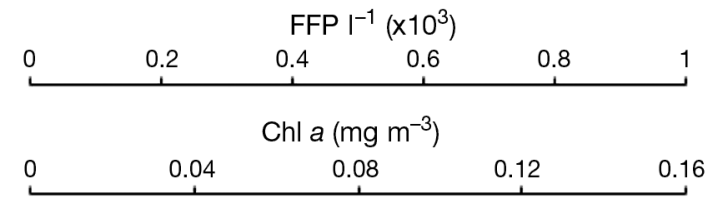
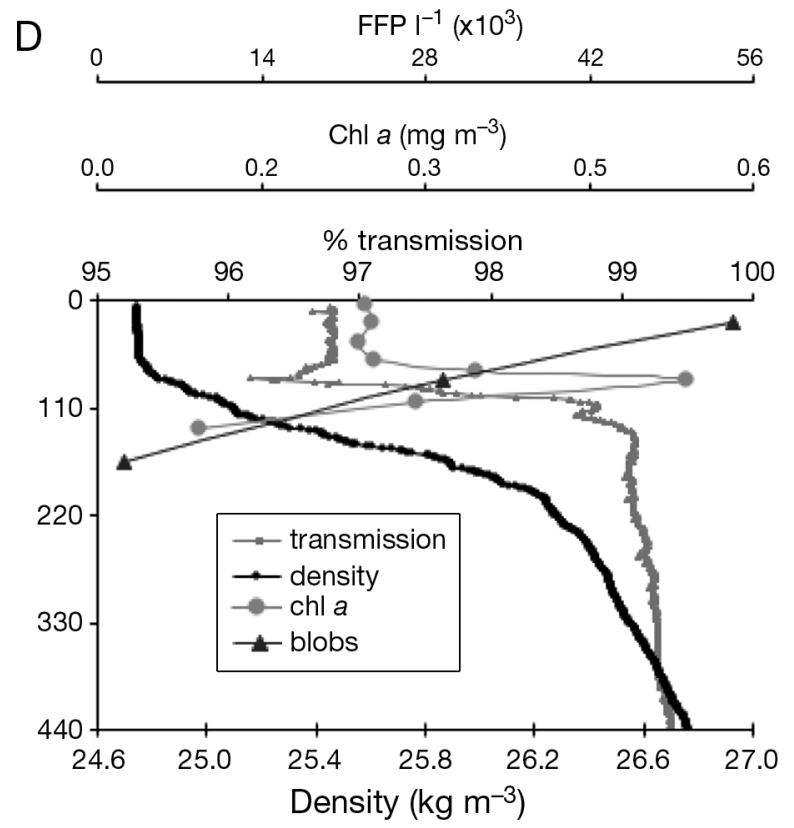

Fig. 3. Seawater density, percent light transmission, chl a and FFP abundance versus depth for the (A) Antarctica shelf and (B) open ocean stations, and the California Current (C) nearshore and (D) offshore stations

ated coalescing of $<0.22 \mu \mathrm{m}$ material. This was also the case for the $\mathrm{Z} / 1000$ and $\mathrm{Z} / 10000$ samples intended to accentuate the potential for DOM aggregation and represents an important observation since dissolved carbon concentrations in these solutions were increased by ca. 6 and $0.6 \mu \mathrm{g} \mathrm{ml}^{-1}$, respectively. The centrifuged sample showed FFP counts of $8.0 \times$
$10^{2} \mathrm{l}^{-1}$ while the whole seawater sample contained $1.8 \times 10^{4} \mathrm{l}^{-1}$.

Addition of hydrophobic exopolymer substances (EPS) isolated from a bacterial culture induces assembly of amphipathic DOM into small gels ( $4 \mu \mathrm{m}$ diameter) in a temperature dependent fashion (Ding et al. 2008). The results from the $0.2 \mu \mathrm{m}$, tangential flow 
filtration (TFF) and temperature controlled samples suggested that the molecular interactions described by Ding et al. (2008) did not cause formation of FFP via networking of DOM by SYBR Gold. Particles could not be detected in the $0.2 \mu \mathrm{m}$ or TFF preparations, in clear contrast to the $4.8 \times 10^{5} \mathrm{l}^{-1}$ found in the natural seawater. The induction of gel formation by EPS was inhibited at $4^{\circ} \mathrm{C}$ in the study of Ding et al. (2008), but we saw no decrease in FFP at this temperature. FFP concentrations were $1.3 \times 10^{4}$ and $6.0 \times 10^{4} \mathrm{l}^{-1}$ for room temperature and $4^{\circ} \mathrm{C}$ treatments, respectively.

\section{Potential experimental artifacts}

\section{Cell lysis in natural seawater}

We considered that FFP might be produced as artifacts of sample processing, e.g. due to cell lysis or sloughing off of cell mucus during filtration. Fig. 4 shows that FFP abundance exhibited slight differences between live and fixed samples. Fixed samples had fewer small FFP, but the abundance of large ones was similar in the fixed and unfixed samples.

We did further tests to rule out protozoan lysis as a source. We centrifuged seawater at low speed and then stained the pellet and supernatant with the standard protocol. FFP were present in the supernatant that was essentially free of larger phytoplankton, so it is unlikely that they are produced from larger phytoplankton owing to sample treatment. The abundance of large and intermediate sized material in the pellet was much greater than in the supernatant, but the abundance of small size classes was not significantly different (data not shown). The pellet contained many pigmented cells and protozoa that stained with the standard protocol, and the supernatant contained some picoeukaryotes and many bacteria.

\section{Phytoplankton lysis in cultures}

Unfixed phytoplankton cultures were stained to see whether some species release cell contents due to staining and slide preparation. Only lightly fluorescent objects were seen and these did not resemble FFP. Furthermore, these objects and phytoplankton were not seen to be associated with one another, e.g. we did not see fluorescing material oozing out of phytoplankton cells. This was also true for Lingulodinium polyedrum, which is notable because L. polyedrum is delicate and highly susceptible to shear forces and osmolarity changes (Lewis \& Hallett 1997). Such a delicate organism might lyse readily when exposed to suction and low osmolarity stain solutions. We could not rule out
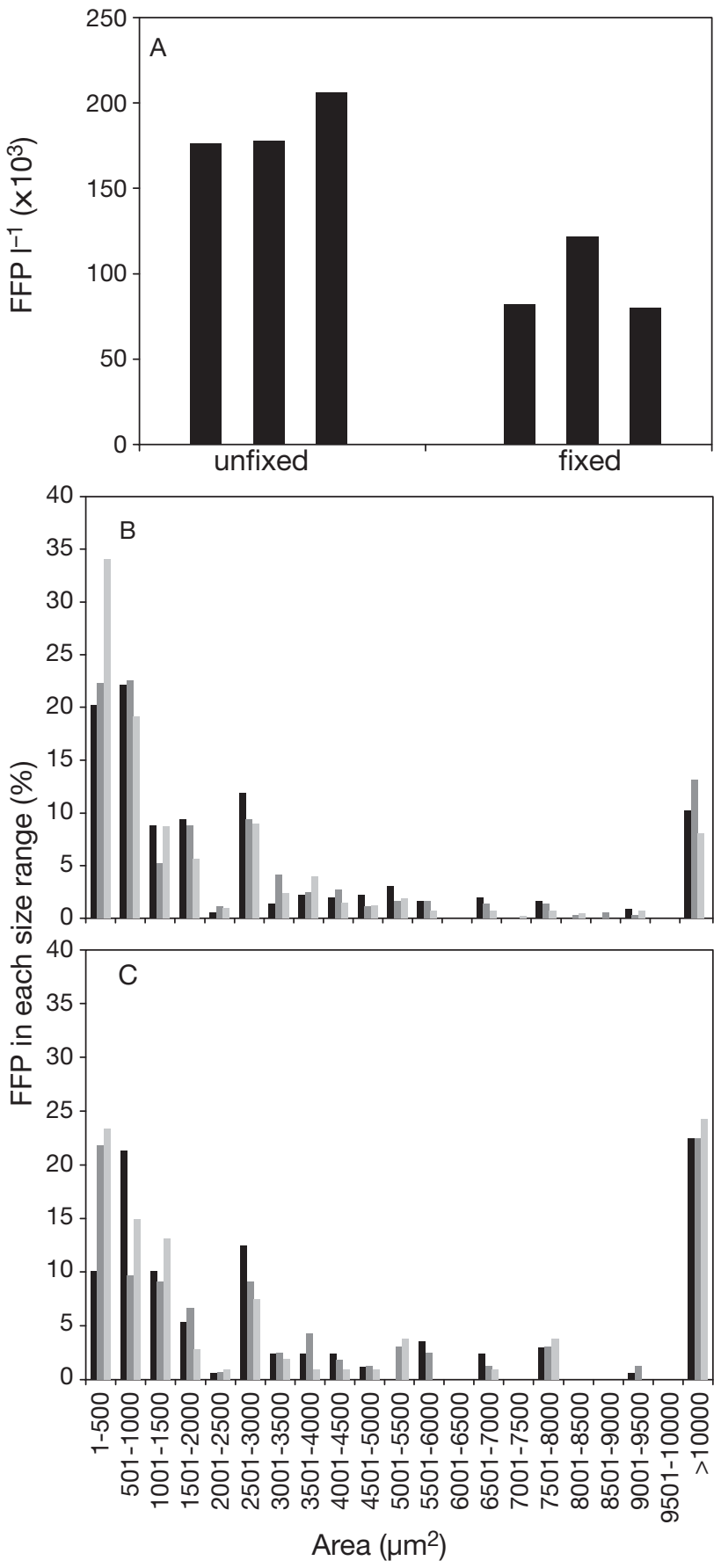

Fig. 4. (A) Abundances of FFP in unfixed and fixed seawater samples. Size frequencies of FFP in (B) unfixed and (C) $2 \%$ formaldehyde fixed seawater samples. Bars in (B) and (C) are shaded for ease of viewing, with black corresponding to the first replicate, grey to the second and light grey to the third

the possible scenario that cell lysis occurs, but the released organic matter can either remain dissolved thus, it is not retained on the filter - or forms gels and particles that are retained and visualized with our 
staining protocol. Chin et al. (2004) showed that Phaeocystis globosa secrete condensed polysaccharide particles that swell up and form gels when released into seawater.

\section{Support for in situ occurrence}

Several lines of evidence support the view that FFP exist in seawater and are not experimental artifacts. FFP were occasionally and to varying degrees colonized by bacteria. It is highly unlikely that bacteria migrated to lysed contents of a cell during or immediately after filtration. Close associations between FFP and non-bacteria/archaea microorganisms were also observed. Individuals of Akashiwo sp. were seen alone and in association with bacteria or FFP within the same sample. The Akashiwo sp. cells associated with FFP appeared intact and unlysed in unfixed and $2 \%$ formaldehyde fixed seawater. Intriguingly, chains of cyanobacteria occasionally co-localized with FFP (Fig. 5), but these were not randomly distributed on the filter. Lastly, TEP often appeared to border FFP and, thus, may be previously unseen extensions of the transparent particle field.

\section{Mechanism of visualization}

Interactions of stains

All tested combinations of Alcian Blue plus SYBR Gold yielded positive staining for FFP. Visualization was optimal when we filtered seawater, stained the retained material with Alcian Blue and placed the filter on a drop of SYBR Gold. Omitting Alcian Blue caused the entire filter to fluoresce brightly and identically to the FFP (Fig. 1C). We think that Alcian Blue quenches the SYBR Gold induced filter background, except where the FFP are located. Crystal Violet and Ruthenium Red provided similar staining results as Alcian Blue although the images were not as bright or distinct. Chemical quenching by Alcian Blue seemed unlikely since the copper center and complex ring structure of Alcian Blue is unlike both the carbon centered triphenylmethane structure of Crystal Violet and the ruthenium center and amine side chains of Ruthenium Red. However, all these stains caused apparent fluorescence quenching of the filter. FFP were the regions of high SYBR Gold background. What is visualized then are the brightly fluorescing pores of the polycarbonate filter in the region of the FFP. Thus, we hypothesized that FFP were regions on the filter where transparent particles landed and prevented Alcian Blue from quenching SYBR Gold induced fluorescence
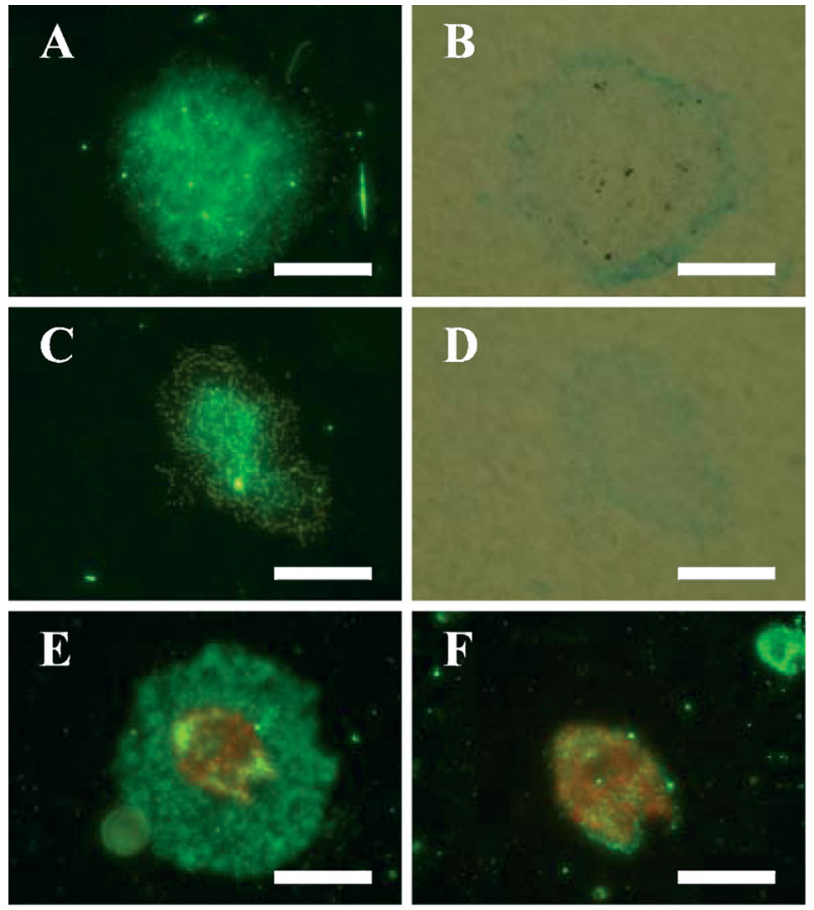

Fig. 5. Epifluorescent micrographs of FFP with extensive populations of associated (A) bacteria, (C) cyanobacteria and (E) Akashiwo sp. Panel (F) shows a Akashiwo cell not surrounded by an FFP signal. Panels (B) and (D) are transmitted light micrographs of (A) and (C), respectively, showing TEP signals along the particle periphery. Scale bars $=50 \mu \mathrm{m}$

by an as yet unknown mechanism. Visualization of transparent organic matter by our protocol is, thus, due to inhibition of fluorescence quenching.

\section{Particle-filter interactions}

Our tests suggested that FFP could be observed because the transparent particles deposited on filters prevented Alcian Blue from interacting with the filter to quench SYBR Gold fluorescence. We attempted to dislodge the transparent particles from the filter with the prediction that this would allow Alcian Blue to quench SYBR Gold fluorescence and eliminate FFP signals. This prediction was supported. We filtered seawater by gravity and then rinsed the filter with filtered seawater to try to dislodge the FFP. This manipulation did nearly eliminate FFP while many microbes and a few positive signals remained. However, the FFP were not removed if the seawater sample (not the water used for dislodging the FFP) had been vacuum filtered at $20 \mathrm{kPa}$, possibly because the material became pulled into the filter pores and firmly adsorbed. This entrainment of material into the pores may be required for Alcian Blue inhibition of SYBR 
Gold fluorescence; it would coat the pores and therefore prevent Alcian Blue interaction with the SYBR Gold-stained filter surface and pores. This result is consistent with our hypothesis that FFP are visualized due the inhibition of fluorescence quenching.

\section{Influence of filters}

To test whether fluorescence quenching was only applicable to polycarbonate filters, we tried other filter materials as well. FFP were also seen with white $0.22 \mu \mathrm{m}$ polycarbonate and $0.45 \mu \mathrm{m}$ nitrocellulose filters and $0.02 \mu \mathrm{m}$ aluminum oxide filters without Alcian Blue treatment. The $0.02 \mu \mathrm{m}$ filters were not amenable to Alcian Blue staining and produced indiscernible images. The black $0.22 \mu \mathrm{m}$ polycarbonate membranes were negative for FFP, presumably due to the black color reducing background fluorescence required for visualization by fluorescence quenching. Alternatively, the black filter might have interfered with interaction of the stains on the filter. Despite positive results with several filter types, the $1 \mu \mathrm{m}$ polycarbonate filter gave images that were best in definition and brightness. With the focal plane on the surface of the filter, the fluorescing edges of the pores contrasted well with the non- or slightly fluorescent interior. The pores of $1 \mu \mathrm{m}$ polycarbonate filters permit resolution of SYBR Gold stained microbes attached to the fluorescing FFP; $0.22 \mu \mathrm{m}$ pore size polycarbonate filter fluorescence is so intense that it overwhelms the fluorescence signal of the SYBR Gold stained organisms.

\section{Seawater and filter manipulation}

\section{Gel properties}

With evidence to support that filter fluorescing particles were present in seawater, we asked whether they display gel or gel-like characteristics. Preliminary experiments (results not shown) indicated that EDTA reduced FFP abundance but not their size distributions, suggesting that cationic bridges bind FFP polymers, and their disruption caused some particles to disperse. Other FFP may have lost some, although not all, material, but maintained their definitions. Recent findings show that the integrity of marine gels is influenced by cationic bridges in a polymer matrix, and that the gels are dispersed by EDTA (Verdugo et al. 2004). The effect of EDTA shows that FFP may be created and maintained in a similar fashion to that of other marine gel particles. They may be intermediate in a stepwise formation of POM from some of the sources of organic matter, going from colloid to gel to filter fluorescing particle to marine snow. We considered that if the FFP material is gel-like it would be highly hydrated, so desiccation might alter its gel characteristics and allow Alcian Blue to contact the filter surface and quench fluorescence. However, attempts to dehydrate the material on the filter actually increased FFP abundance. In addition, the size distribution of FFP increased with an increase in abundance of FFP from 5500 to $>10000 \mu^{2}$ in one experiment. We cannot explain this result, but speculate that dehydration changed the properties of some other types of transparent particles to confer on them the ability to cause inhibition of fluorescence quenching similar to the action of FFP. Alternatively, the initial entrapment of material within the filter pores before dehydration may have provided a source of molecules that, after dehydration, were capable of the inhibitory effect.

Triton X-100 addition followed by sonication decreased the abundance of total as well as large FFP. One interpretation would be that FFP are amphipathic, with hydrophobic regions holding an aggregate together while the hydrophilic areas are exposed to water. Alternatively, FFP may be sensitive to turbulence and shear.

\section{Macromolecular characterization}

In an attempt to constrain the composition, we tested how known macromolecules added to the samples would appear in the standard protocol. We tested DNA, carbohydrate, protein and lipid since they are among the major organic matter pools in marine biomass and DOM. Positive staining was seen with DNA at concentrations of 100 and $1 \mathrm{mg} \mathrm{ml}^{-1}$. Also, BSA and DNA mixed in agarose were prepared as mimics of natural gels. They produced fluorescence similar to FFP. Phosphatidylcholine, as a model for lipids, also yielded FFP-like images. Natural marine gels and particles are probably mixtures of diverse macromolecules (Long \& Azam 1996) so our results show that FFP images may be due to a variety of macromolecular types. Further, the requirement for quite high macromolecular concentrations suggests the possibility that we are still missing some transparent gels because they contain macromolecules at concentrations too low to cause detectable inhibition of fluorescence quenching.

Specific hydrolytic enzymes helped further characterize the macromolecular makeup of FFP by their breakdown or solubilization. $\beta$-glucosidase caused the most apparent decrease in abundances, reducing numbers to $65 \%$ of their total and eliminating most of the large size classes. DNase and pronase treatments 
did not seem to appreciably alter size frequencies and resulted in abundances of 96 and $94 \%$ of the total, respectively. Interestingly, lipase resulted in a slight increase in abundance (104\%), but no change in size frequency distribution. One possibility is that lipid hydrolysis reduced hydrophobic sites and permitted agglomeration of materials at exposed hydrophilic and polar surfaces (Fig. 6).

Assessing the presence of sugar moieties within the FFP via fluorescently labeled lectins provided intriguing chemical and structural information. Positive signals from concavalin A indicated the presence of glucose and/or mannose. The absence of signal co-localization with peanut agglutinin fluorescence suggested that galactose residues were either absent in the FFP or below detection. Sugar-binding moieties displayed a striking interior structure of strings and strands that varied among FFP (Fig. 7). The fact that glucose is a significant fraction of organic matter in FFP would make them a good source of energy for the colonizing bacteria. It is noteworthy that lectin signals always remained within the boundaries of the SYBR Gold fluorescence image, but in many cases did not uniformly occur over the entire FFP. Other organic polymers may occupy the lectinnegative areas.

\section{Nitrogen and phosphorous amendment}

We examined the relationship of FFP with nutrient status of the phytoplankton. Nutrient limited phytoplankton may release gels, so one could predict that phytoplankton will be found associated with FFP. In support of this hypothesis, we consistently noticed that phytoplankton occurred within FFP and occasionally bacteria also colonized the FFP. We considered that if nutrient limited phytoplankton produced mucus that generated the FFP, then high rates of nutrient remineralization within the FFP, due to high concentrations of
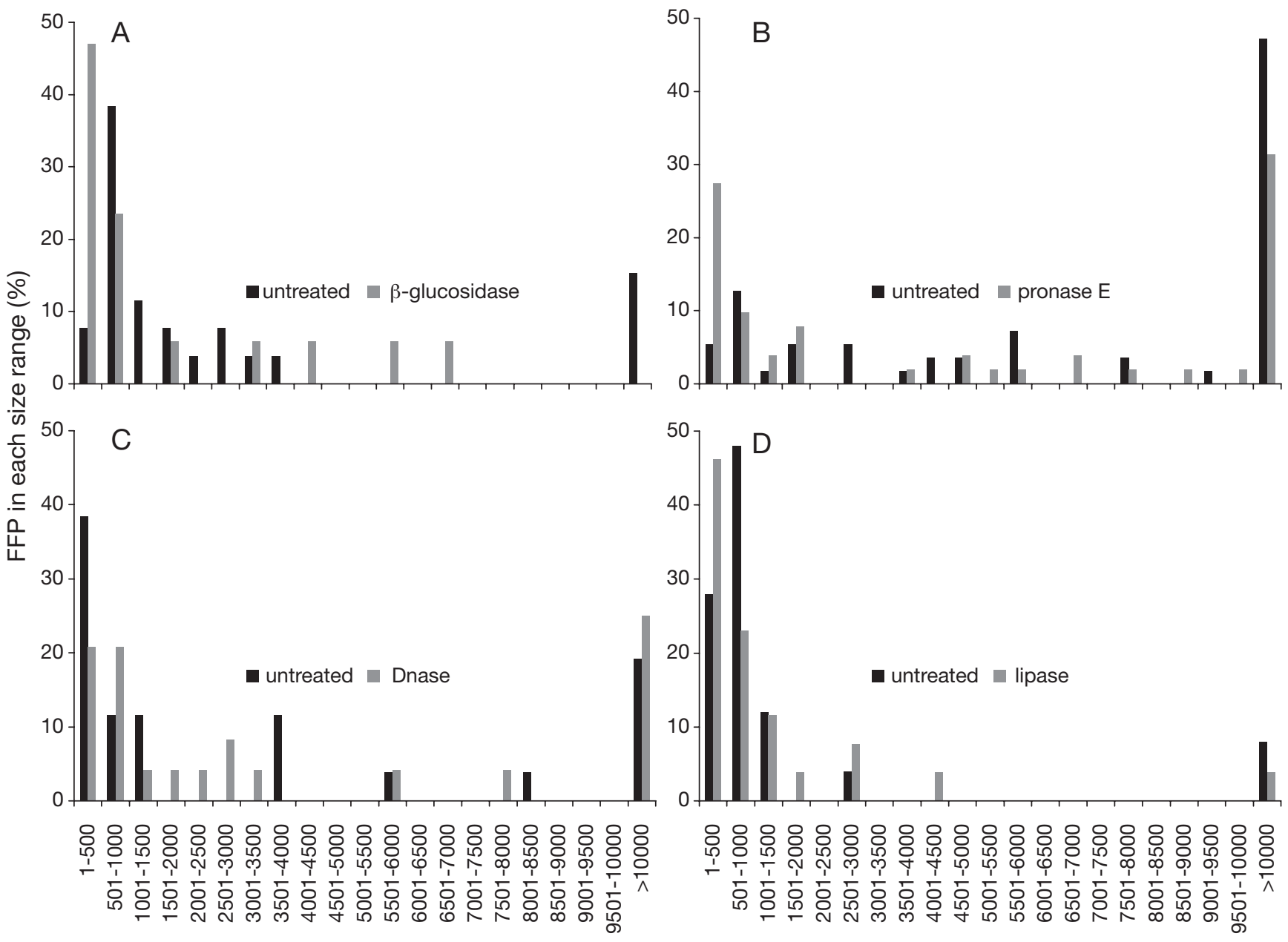

Area $\left(\mu \mathrm{m}^{2}\right)$

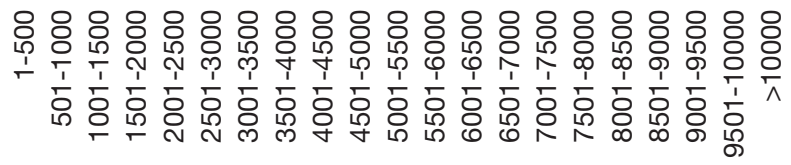

Area $\left(\mu \mathrm{m}^{2}\right)$

Fig. 6. Size frequency charts following treatment with (A) $\beta$-glucosidase, (B) pronase, (C) DNase and (D) lipase 

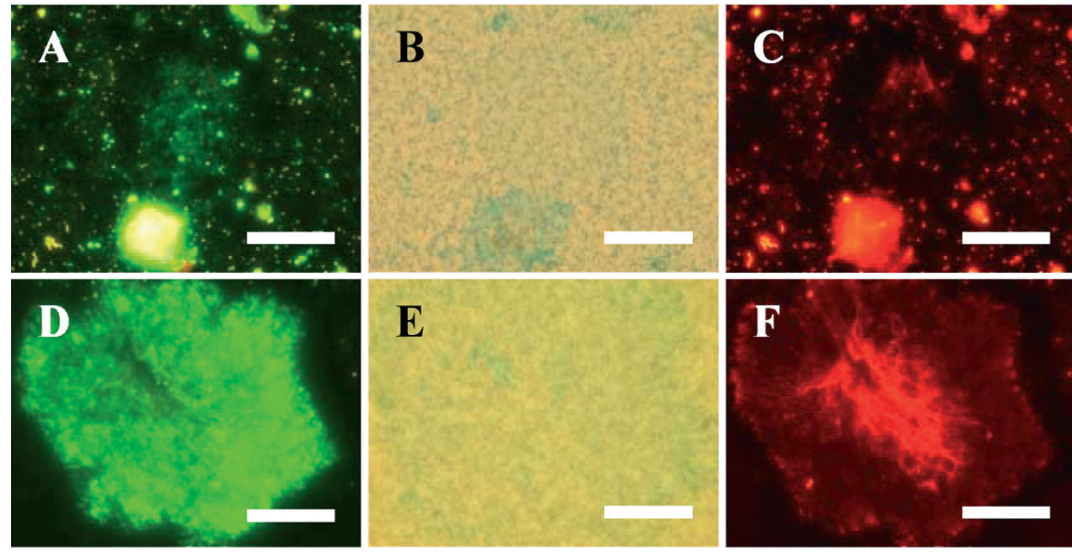

Fig. 7. Each horizontal row of images shows a single FFP visualized with: $(A, D)$ $488 \mathrm{~nm}$ excitation, long pass emission to observe SYBR Gold, (B,E) transmitted light to observe acidic mucopolysaccharide material stained by Alcian Blue, and $(\mathrm{C}, \mathrm{F}) 540 \mathrm{~nm}$ excitation, long pass emission to observe concanavalin A lectin localization. Scale bars $=50 \mu \mathrm{m}$

bacteria and phytoplankton, might have a negative feedback on mucus production. Increased exudation of organic matter by phytoplankton with high C:N ratios occurs during periods of nutrient deprivation. Various explanations for enhanced exudation include (1) reductant overflow and (2) adaptive strategy of the phytoplankton cell to improve the nutrient status of its microenvironment (Azam \& Smith 1991, Borsheim et al. 2005). Exudates of nutrient stressed phytoplankton are rich in carbohydrates, low in nitrogen, probably sticky and subsequently consumed by bacteria. Azam \& Malfatti (2007) proposed that bacteria hydrolyze and metabolize the exuded polymers and DOM adsorbed onto the 'phycosphere' such that $\mathrm{N}, \mathrm{P}$ and $\mathrm{Fe}$ in the phytoplankton cell microenvironment becomes available at high concentrations.

The water off Scripps Pier is typically P-replete but $\mathrm{N}$-limited for phytoplankton growth. We added $1 \mu \mathrm{M}$ ammonium nitrate to try to overcome $\mathrm{N}$ limitation with the prediction that this would reduce FFP production. Rather than lowering the FFP abundance, it actually increased it. Smaller particle size classes increased, but did not resemble the particles in unenriched samples (Fig. 8). Larger size FFP also showed a small increase. Even though the water off Scripps Pier is generally rich in $\mathrm{P}$ (typically 0.3 to $1 \mu \mathrm{M}$ ), $\mathrm{P}$ enrichments decreased FFP abundance and did not change the size range. Bacteria were found attached to FFP in both $\mathrm{N}$ and $\mathrm{P}$ treatments, but attachment in the $\mathrm{N}$ replete samples was particularly noticeable due to the large number of FFP present. The observed increase in the $\mathrm{N}$-replete treatment might be due to enhanced phytoplankton production and its processing by grazers, which lead to spills of stainable polymers into seawater. The N-replete conditions may also have changed the chemical composition of the released polymer pool and, thus, its stainability. We conclude that the nutrient status of seawater can affect FFP dynamics, and also influence the associated microbial community. However, this preliminary experiment does not address the mechanism regulating FFP formation.

\section{CONCLUSIONS}

Our discovery extends the types of transparent particles known to be present in seawater. As has been proposed for the ecological role of TEP, DAPI yellow particles (DYP) and CSP, these FFP may also provide microenvironments of high microbial activity (Alldredge et al. 1993, Mostajir et al. 1995, Long \& Azam 1996). Their chemical and physical diversity may lead to great microbial diversity and assorted biogeochemical transformations.

It is critical to rule out that the particles seen are not due to artifacts and indeed are present in seawater. This challenge has been faced by oceanographers from the discoveries of Bathybius (Huxley 1868), TEP, CSP, Koike particles (Isao et al. 1990), gels and colloids (Wells \& Goldberg 1991, Chin et al. 1998), as well as the FFP here. Ideally one would want to image particles as they exist in seawater, without physically sampling them. The technology to do so may become available in the future (Franks \& Jaffe 2001, GonzalezQuiros \& Checkley 2006). At present, to rule out artifacts while at the same time learn more about the chemical and physical characteristics of the particles, multiple constraints can be applied, as we have done in this study. The potential sources of FFP and other transparent particles are probably diverse. Many microorganisms release polymers by exudation, exocytosis or programmed cell death (PCD). However, identifying the type of transparent particles and relating them to their sources is confounded by the diversity of particles as well as microorganisms and their in situ physiologies. Berman-Frank et al. (2007) found that cultures of the cyanobacterium Trichodesmium increased TEP production following PCD in response to nutrient and/or oxidative stress. Notably, iron limitation was correlated with PCD and the highest pools of TEP and particulate organic carbon. Whether the same would be true for FFP was not tested. The diverse sources and production mechanisms are probably reflected in their chemical composition (Long \& Azam 

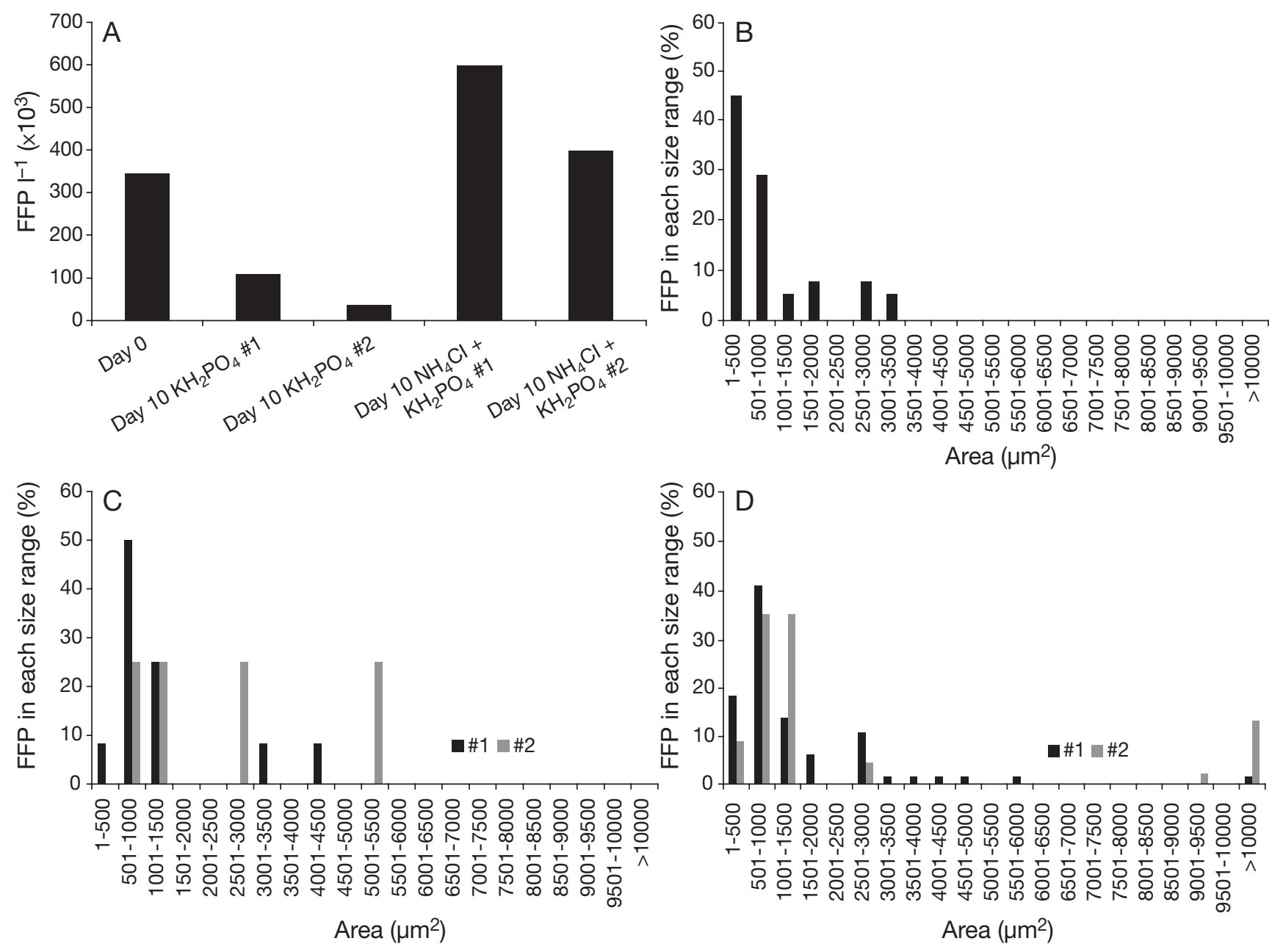

Fig. 8. (A) Abundances at Days 0 and 10 with and without amendments. Size frequencies of FFP at (B) Day 0, (C) Day 10 following amendment with phosphorus and (D) Day 10 following amendment with nitrogen plus phosphorus. Black and gray bars in (C) and (D) display the first and second replicates, respectively

1996, Passow 2002, Verdugo et al. 2004). Our results indicate that a variety of macromolecules - carbohydrates, DNA, lipids and proteins - can elicit positive signals in our protocol. It would be of interest to see whether the standard Alcian Blue/SYBR Gold protocol may also be applied to staining for other types of transparent particles and sources.

If we consider that FFP and other transparent particles behave in a fashion similar to polymer gels, then local changes in the chemistry of seawater will result in shrinking and swelling of the material. The effects of pressure, temperature and pollutants may cause a gel to become a highly compact and dense structure, capable of excluding or entrapping anything less than 500 Da (Chin et al. 1998). Alcian Blue has an atomic weight of approximately $1200 \mathrm{Da}$, and it may follow that the use of histological stains greater than 1200 Da will permit staining of more diffuse and/or porous particles. Observing this material and associ- ated microbes may aid in linking microbial physiology and diversity to the state of the organic matter field in seawater. This may be especially important in understanding carbon export and the fates of organic particles.

Whether some dissolved polymers, colloids and gels might sink out of the euphotic zone will depend on many factors, such as the speed and degree of substrate hydrolysis, the chemical composition and stickiness of the material, the consortia of organisms present and the local physical and chemical characteristics of the water column, and whether respiration will convert most of the fixed carbon back to its oxidized state. A common theme among these parameters is the phenomenon of aggregation and its relation to export flux, with implications for global climate. As a particle is hydrolyzed and colonized by the microbial community and comes into contact with other particles and molecules, the resulting changes in density may have direct 
connections to carbon export. However, it is currently unclear whether the net biological, chemical and physical effects enable carbon drawdown. These processes are not necessarily limited to microscale environments, as a variety of metazoans may also significantly affect the particulate carbon pool. The copepod Calanus pacficus consumes significant amounts of TEP under starved and diatom-replete conditions (Ling \& Alldredge 2003). FFP may represent another pathway by which higher trophic levels are able to consume viruses, prokaryotes and small eukaryotes located on or within the organic matrix. Further characterization of marine organic matter, its interactions with marine microbes and its behavior in a microecological framework would advance our knowledge of the mechanisms operating at the microscale that contribute to oceanic biogeochemical cycles.

Acknowledgements. This research was supported by grants from the US-NSF (OCE04-28900 and ANT04-44134) and the Gordon and Betty Moore Foundation to F.A. Additional support was provided by US-NSF funding for the California Current Ecosystem Long Term Ecological Research (CCE-LTER) to Dr. M. D. Ohman (OCE04-17616). We thank the Captains and crews of the RV/IB 'Nathaniel B. Palmer and R/V Thomas G. Thompson' for excellent shipboard support. We appreciate the assistance of J. V. Nguyen and Drs. M. Manganelli and J. R. Ward in sample collection.

\section{LITERATURE CITED}

Alldredge AL, Passow U, Logan BE (1993) The abundance and significance of a class of large, transparent organic particles in the ocean. Deep-Sea Res I 40:1131-1140

Aluwihare LI, Repeta DJ (1999) A comparison of the chemical characteristics of oceanic DOM and extracellular DOM produced by marine algae. Mar Ecol Prog Ser 186:105-117

Aluwihare LI, Repeta DJ, Chen RF (1997) A major biopolymeric component to dissolved organic carbon in surface sea water. Nature 387:166-169

Azam F, Long RA (2001) Oceanography: sea snow microcosms. Nature 414:495-498

> Azam F, Malfatti F (2007) Microbial structuring of marine ecosystems. Nat Rev Microbiol 5:782-791

Azam F, Smith DC (1991) Bacterial influence on the variability in the ocean's biogeochemical state: a mechanistic view. In: Demers S (ed) Particle analysis in oceanography, Vol 27. Springer-Verlag, Berlin, p 213-236

> Azam F, Worden AZ (2004) Microbes, molecules, and marine ecosystems. Science 303:1622-1624

Azam F, Martinez J, Smith DC (1993) Bacteria-organic matter coupling on marine aggregates. In: Guerrero R, PedrósAlió C (eds) Trends in microbial ecology. Spanish Society for Microbiology, Barcelona, p 410-414

Berman-Frank I, Rosenberg G, Levitan O, Haramaty L, Mari $\mathrm{X}$ (2007) Coupling between autocatalytic cell death and transparent exopolymeric particle production in the marine cyanobacterium Trichodesmium. Environ Microbiol 9:1415-1422

Borsheim KY, Vadstein O, Myklestad SM, Reinertsen H,
Kirkvold S, Olsen Y (2005) Photosynthetic algal production, accumulation and release of phytoplankton storage carbohydrates and bacterial production in a gradient in daily nutrient supply. J Plankton Res 27:743-755

Chin WC, Orellana MV, Verdugo P (1998) Spontaneous assembly of marine dissolved organic matter into polymer gels. Nature 391:568-572

Chin WC, Orellana MV, Quesada I, Verdugo P (2004) Secretion in unicellular marine phytoplankton: demonstration of regulated exocytosis in Phaeocystis globosa. Plant Cell Physiol 45:535-542

> DeLong EF, Karl DM (2005) Genomic perspectives in microbial oceanography. Nature 437:336-342

Ding YX, Chin WC, Rodriguez A, Hung CC, Santschi $\mathrm{PH}$, Verdugo P (2008) Amphiphilic exopolymers from Sagittula stellata induce DOM self-assembly and formation of marine microgels. Mar Chem 112:11-19

Franks PJS, Jaffe JS (2001) Microscale distributions of phytoplankton: initial results from a two-dimensional imaging fluorometer, OSST. Mar Ecol Prog Ser 220:59-72

> Gonzalez-Quiros R, Checkley DM (2006) Occurrence of fragile particles inferred from optical plankton counters used in situ and to analyze net samples collected simultaneously. J Geophys Res-Oceans 111:C05S06

Grossart HP, Kiorboe T, Tang KW, Allgaier M, Yam EM, Ploug $\mathrm{H}$ (2006) Interactions between marine snow and heterotrophic bacteria: aggregate formation and microbial dynamics. Aquat Microb Ecol 42:19-26

Huxley TH (1868) On some organisms living at great depths in the North Atlantic Ocean. Q J Microsc Sci 8:203-212

> Isao K, Hara S, Terauchi K, Kogure K (1990) Role of submicrometre particles in the ocean. Nature 345:242-244

Johnsen AR, Hausner M, Schnell A, Wuertz S (2000) Evaluation of fluorescently labeled lectins for noninvasive localization of extracellular polymeric substances in Sphingomonas biofilms. Appl Environ Microbiol 66: 3487-3491

Kiørboe T, Tang K, Grossart HP, Ploug H (2003) Dynamics of microbial communities on marine snow aggregates: colonization, growth, detachment, and grazing mortality of attached bacteria. Appl Environ Microbiol 69: 3036-3047

Lewis J, Hallett R (1997) Lingulodinium polyedrum a blooming dinoflagellate. In: Ansell AD, Gibson RN, Barnes M (eds) Oceanography and marine biology: an annual review, Vol 35. UCL Press, London, p 97-161

Ling SC, Alldredge AL (2003) Does the marine copepod Calanus pacificus consume transparent exopolymer particles (TEP)? J Plankton Res 25:507-515

Long RA, Azam F (1996) Abundant protein-containing particles in the sea. Aquat Microb Ecol 10:213-221

Long RA, Azam F (2001) Microscale patchiness of bacterioplankton assemblage richness in seawater. Aquat Microb Ecol 26:103-113

> Mostajir B, Dolan JR, Rassoulzadegan F (1995) Seasonal variations of pico- and nano-detrital particles (DAPI Yellow Particles, DYP) in the Ligurian Sea (NW Mediterranean). Aquat Microb Ecol 9:267-277

Noble RT, Fuhrman JA (1998) Use of SYBR Green I for rapid epifluorescence counts of marine viruses and bacteria. Aquat Microb Ecol 14:113-118

> Orellana MV, Petersen TW, Diercks AH, Donohoe S, Verdugo P, van den Engh G (2007) Marine microgels: optical and proteomic fingerprints. Mar Chem 105:229-239

> Passow U (2002) Production of transparent exopolymer particles (TEP) by phyto- and bacterioplankton. Mar Ecol Prog Ser 236:1-12

Passow U, Alldredge AL (1994) Distribution, size and bacter- 
ial-colonization of transparent exopolymer particles (TEP) in the Ocean. Mar Ecol Prog Ser 113: 185-198

Proctor LM, Fuhrman JA (1991) Roles of viral infection in organic particle flux. Mar Ecol Prog Ser 69:133-142

Radic T, Ivancic I, Fuks D, Radic J (2006) Marine bacterioplankton production of polysaccharidic and proteinaceous particles under different nutrient regimes. FEMS Microbiol Ecol 58:333-342

Simon M, Grossart HP, Schweitzer B, Ploug H (2002) Microbial ecology of organic aggregates in aquatic ecosystems. Aquat Microb Ecol 28:175-211

Smith DC, Steward GF, Long RA, Azam F (1995) Bacterial

Editorial responsibility: Craig Carlson,

Santa Barbara, California, USA mediation of carbon fluxes during a diatom bloom in a mesocosm. Deep-Sea Res II 42:75-97

Verdugo P, Alldredge AL, Azam F, Kirchman DL, Passow U, Santschi PH (2004) The oceanic gel phase: a bridge in the DOM-POM continuum. Mar Chem 92:67-85

Wells ML, Goldberg ED (1991) Occurrence of small colloids in sea-water. Nature 353:342-344

Zipper H, Brunner H, Bernhagen J, Vitzthum F (2004) Investigations on DNA intercalation and surface binding by SYBR Green I, its structure determination and methodological implications. Nucleic Acids Res 32:e103, doi:10.1093/nar/gnh101

Submitted: March 4, 2008; Accepted: September 23, 2008

Proofs received from author(s): December 12, 2008 